\title{
Longitudinal association between interparental conflict and risk-taking behavior among Chinese adolescent: Testing a moderated mediation model
}

\author{
Wan-Yu Ye ${ }^{1}$, Kai Dou ${ }^{1}$, Lin-Xin Wang ${ }^{1}$, Xiao-Qi Lin ${ }^{1}$, and Ming-Chen Zhang ${ }^{1}$ \\ ${ }^{1}$ Department of Psychology and Research Center of Adolescent Psychology and Behavior, \\ School of Education, Guangzhou University
}

There are no conflicts of interest to declare. This work has supported a grant by the National Natural Science Foundation of China (No. 31800938), the 13th Five-Year Plan of Philosophy and Social Science of Guangzhou (No. 2020GZYB92), and the Guangzhou Education Scientific Research Project (No. 202113700) to Kai Dou. Correspondence concerning this article should be addressed to Kai Dou, Department of Psychology and Research Center of Adolescent Psychology and Behavior, Guangzhou University. Guangzhou Higher Education Mega Center, 230, Waihuan Road West, Panyu District, Guangzhou, P. R. China.E-mail: psydk@gzhu.edu.cn 


\begin{abstract}
Objective: Grounded in ecological system theory, this study considers the longitudinal association between interparental conflict (IPC) and risk-taking behavior among adolescents and investigates the underlying mediating and moderating mechanisms.
\end{abstract}

Background: IPC has been shown to have a detrimental impact on adolescent behavior development. However, little is known about the processing mechanisms underlying the association of IPC and risktaking behavior from an ecosystem perspective.

Method: This study conducted a longitudinal design (3 time points, 3 months apart) with the sample comprising 550 middle school students in southeastern China (52.91\% males; mean age at Time $1=$ 15.37). The performed measurements encompassed IPC (T1), deviant peer affiliation(T2), school climate (T3), risk-taking behavior (T1/T2/T3), and demographic information.

Results: The moderated mediation model revealed that after controlling for T1/T2 risk-taking behavior, T1 IPC was longitudinally and positively correlated with T3 risk-taking behavior through T2 deviant peer affiliation. Furthermore, the indirect effect of $\mathrm{T} 2$ deviant peer affiliation was significantly stronger under a low-level T3 school climate.

Conclusion: Adolescent risk-taking behavior is the joint effect of risk factors from multiple microsystems. Specifically, IPC is associated with higher levels of deviant peer affiliation, which, in turn, are associated with more risk-taking behavior. Moreover, the negative school climate serves as a risk factor to enhance the adverse impact of deviant peer affiliation on adolescents' risk-taking behavior.

Keywords: Interparental conflict, Risk-taking behavior, Deviant peer affiliation, School climate 


\section{INTRODUCTION}

Interparental conflict (IPC) is physical aggression or verbal conflict between parents due to disagreement or other reasons (López-Larrosa et al., 2019). More importantly, IPC is associated with negative behavioral outcomes, such as risk-taking behavior (Capaldi et al., 2020; Koçak et al., 2017; van Eldik et al., 2020). However, the detailed mechanism underlying the process remains poorly understood. During adolescence, as the relationship of primary importance shifts from parents to peers, interactions with peers become especially salient (Kopec et al., 2018). A negative family environment (such as one with IPC) may transmit risks to peer relationships (e.g., deviant peer affiliation (DPA)) and reinforce risk-taking behavior (Weymouth et al., 2019; Zhang et al., 2021). In addition to family and peer effects, school is another crucial context essential to adolescents' behavior development (Caravita et al., 2021; Coelho et al., 2020). As a protective factor, school climate can buffer the adverse effect of a negative environment (Sznitman \& Romer, 2014; Wang \& Dishion, 2012). In contrast, a low-level school climate adversely affects adolescents' behavior development (Yang et al., 2020). Although several studies have great implications on how a single ecosystem (i.e., family, peer, school) affects risk-taking behavior among adolescents (Chen et al., 2020; Davies et al., 2018; Walker \& Holtfreter, 2019), little empirical evidence explains the underlying mechanism of risk-taking behavior from a multiple ecological systems perspective (Bronfenbrenner, 1979). Hence, this study constructed a moderated mediation model based on ecological system theory in a sample of Chinese high school students to explore the risk transmission path by which IPC affects adolescent risk-taking behavior, the mediating role of DPA, and the moderating role of school climate.

\section{Risk-taking behavior and interparental conflict}

Adolescence is marked by a steep increase in risk-taking behavior, which can be defined as the 
behavior carried out by individuals in the condition of knowing potential risks or negative consequences in pursuit of a favorable result, such as violent crime, alcohol abuse, risky driving, and unsafe sex (Ben-Zur \& Zeidner, 2009; Ju et al., 2020; Sanci et al., 2018). Numerous studies have demonstrated that compared to adults and children, adolescents are more likely to engage in risktaking behavior regardless of the adverse consequences, which is detrimental to their physical and mental health (Albert \& Steinberg, 2011; Duell et al., 2018; Freeman et al., 2020). Therefore, it is crucial to explore factors affecting adolescents' risk-taking behavior. A particularly critical factor is family, and an unfavorable family environment harms adolescents' growth (Keeports \& Pittman, 2016; Orgiles et al., 2015). For example, IPC impacts not only family members' relationships but also behavior patterns and further increases risk-taking behavior (Dou et al., 2020; Martin et al., 2019; Wang et al., 2021).

Based on the family system, family plays a key role in affecting adolescent development (Bowen, 1966). IPC creates a negative family climate and promotes adolescents to take more risks under the pressure of the family environment (Ohannessian \& Vannucci, 2020). This view has been supported by empirical evidence that IPC decreases parents' quality of parenting and coparenting time, which leads to more negative risk-taking behavior among adolescents (Dou et al., 2020; O'Hara et al., 2019). Moreover, destructive and intense IPC contributes to teenagers' emotional distress (e.g., anger, selfblame), which leads them to seek smoking, drinking, and physical aggression as a means of coping with emotional problems (Brock \& Kochanska, 2016; Fosco et al., 2014). Davies et al. (2016) indicated that adolescents who experience high-frequency IPC from childhood to adolescence, which increases their indifferent interaction between parents, and in the process, perceived insecurities about parental and parent-child relationships, which may increase their risk-taking behavior. It follows that 
INTERPARENTAL CONFLICT AND RISK-TAKING BEHAVIOR

IPC fosters a negative parenting environment, affects adolescent emotional regulation and development, and increases the risk of individual negative risk-taking behavior.

\section{The mediation effect of deviant peer affiliation}

The core of relationships shifts from family to peers during adolescence. Adolescents' choices of friends affect their behavioral development. DPA is adolescents' selective association with peers who violate rules, social ethics, and laws (Rudolph et al., 2014) and is a risk factor for increased risktaking behavior among adolescents (Dou et al., 2020; McCoy et al., 2017). Social learning theory suggests that adolescents learn more risk-taking behavior through observation and imitation when socializing with deviant peers (Thompson et al., 2020; Walker \& Holtfreter, 2019). Furthermore, adolescents obtain support and defend their high position in the deviant peer's status hierarchy by showing risk-taking behavior, such as smoking and alcohol use (Daspe et al., 2019).

Family and peers are two such microsystems found to directly, indirectly, and interactively affect multiple aspects of adolescent development according to ecological system theory (Bronfenbrenner, 1979). Specifically, one ecological risk factor in the microsystem (i.e., IPC) might increase the likelihood of adolescents being exposed to another risk factor (i.e., DPA), which in turn promotes risk-taking behavior (Dou et al., 2020; López-Larrosa et al., 2019). Recent research has demonstrated that adolescents apply the conflicting communication strategies (e.g., assault, abuse) learned in IPC to peer interactions, which may result in risk-taking behavior (e.g., risky driving, alcohol use; Davies et al., 2018; Hebert et al., 2019). Additionally, destructive IPC threatens adolescents' sense of safety and support from their families, which may further create conditions conducive to adolescents seeking to affiliate with deviant peers and increase risk-taking behavior (Blakemore, 2018; Lux \& 
Walper, 2019). In light of this information, IPC makes adolescents vulnerable to the negative effects of deviant peers and impulsive risk-taking behavior (Davies et al., 2018; Dou et al., 2020).

\section{The moderation effect of school climate}

School is a central environment in which the vast majority of adolescents interact daily (Bronfenbrenner, 1979; Varela et al., 2021) and may operate together with DPA to explain why IPC is associated with risk-taking behavior. Specifically, school climate, which is a lasting and stable environmental characteristic, can reflect all aspects of the school experience of adolescents (e.g., teacher-student relationship, student engagement; Wang et al., 2017). A longitudinal study demonstrated that the normative standards of behavior that adolescents perceive decrease and risktaking behavior tends to increase under a negative school climate (Dorio et al., 2019). In addition, adolescents' negative perceptions of school climate were associated with increased psychological and behavioral difficulties (Sullivan et al., 2021). More importantly, according to ecological systems theory (Bronfenbrenner, 1979), negative connections between microsystems may have negative consequences. That is, a negative school climate may operate as a risk factor and strengthen the deleterious effects of DPA on adolescents' risk-taking behavior (Bao et al., 2020).

In contrast, based on the stress-buffering model, positive factors in one context may buffer the impacts of risk factors in another context on adolescents' development outcomes. Consistent with this model, we claim that a positive school climate moderates the association between IPC and risktaking behavior. Previous studies have proven that a positive school climate meets the psychological needs of adolescents and reduces risk-taking behavior (Bao et al., 2020; Crosnoe et al., 2002; Sznitman et al., 2014). Moreover, adolescents can obtain emotional support and help from teachers 
in a positive school climate; with this, adolescents may reduce the possibility of adopting negative stress coping strategies (e.g., risk-taking behavior) and better navigate the stress brought by DPA (Loukas et al., 2016; Peng et al., 2020).

Thus, the variety of school climate might be an important variable for differences in adolescents' risk-taking behavior. Based on previous research, we propose that a low-level school climate may facilitate the intensified effect of DPA on risk-taking behavior, while a high-level school climate may attenuate this relation.

\section{The current study}

Environmental factors, such as family, peer, and school context, play a role in adolescent risktaking behavior. Based on the perspective of ecological system theory, this study comprehensively considers family, peers, and school environmental perspectives to reveal the mechanism by which adolescents' risk-taking behavior is affected. Specifically, the present study explored the longitudinal relations between IPC and risk-taking behavior in a Chinese sample and the mechanism of DPA and school climate.

We hypothesized that IPC positively predicts adolescent risk-taking behavior (Hypothesis 1), DPA mediates the association between IPC and risk-taking behavior (Hypothesis 2), school climate moderates the association between DPA and risk-taking behavior (Hypothesis 3a), and school climate moderates the mediation effect of DPA(Hypothesis 3b). The research model is shown in Figure 1.

[INSERT FIGURE 1 IN HERE]

METHOD 
We used a convenient sampling method to recruit 550 adolescents $\left(M_{\text {age }}=15.37\right.$ years, $S D=$ 1.35; 291 boys and 259 girls) in a southern city in China in September 2018 (Time 1, T1). Three months later (Time 2, T2), we used the same procedure and $97.3 \%$ of the initial sample $(N=535,279$ boys and 256 girls). Another three months later (Time 3, T3), 513 adolescents (269 boys and 244 girls) remained in the study (attrition rate $=6.7 \%$ ). The participants who were absent in data collection at each time point were excluded. The majority of the participants' parents had a high school degree, $39.8 \%$ of the fathers had a middle school degree, $47.4 \%$ had earned a college degree or equivalent, and $9.0 \%$ had earned a graduate degree; $44.4 \%$ of the mothers had a middle school degree, $44.2 \%$ had earned a college degree or equivalent, and 5.4\% had earned a graduate degree.

\section{Procedure}

Ethical approval was obtained from the ethics committee of the corresponding author's university (Protocol Number: bland). We received oral and written consent from all participants, and their parents provided written consent before data collection. Before providing informed consent, all participants were informed of their right to freely drop out of the study at any time with no further obligations. The procedures followed a standardized protocol implemented by trained research assistants to collect data during regular school hours. This procedure was repeated for all collection time points. After completing the study, all the participants received a gift for their participation.

\section{Measures}

\section{Interparental conflict (IPC)}

IPC was assessed by the Interparental Conflict subscale from the Children's Perception of Interparental Conflict questionnaire at T1 (Buehler et al., 1998; Kerig, 1996). The questionnaire 
INTERPARENTAL CONFLICT AND RISK-TAKING BEHAVIOR

consists of 7 items that evaluate the frequency of IPC in the past. The participants responded on a four-point scale ranging from $1=$ never to $4=$ very often, with higher scores indicating more frequent IPC. Sample items included "How often do your parents threaten each other when they disagree". The Chinese version of the IPC presented good internal consistency (Xu et al., 2021). The Cronbach's alpha value for the scale was 0.82 in the current study.

\section{Deviant peer affiliation (DPA)}

DPA was measured at T2 using the ten-item Deviant Peer Affiliation Questionnaire (Bao et al., 2015; Chen et al., 2015). The participants reported the number of friends who engaged in certain deviant behaviors (e.g., cheating in exams, gambling, or stealing) on a 5-point scale ranging from 1 $=$ none to $5=$ more than six. The Chinese version of the DPA has demonstrated good internal consistency in adolescents (Dou et al., 2020). The Cronbach's alpha in this study was 0.86 .

\section{School climate}

The participants' perceived school climate was assessed by the school climate questionnaire (SC) at T3 (Bear et al., 2011; Bear et al., 2014). The SC consists of 28 items that evaluate seven dimensions of school climate: teacher-student relations, student-student relations, student engagement-schoolwide, clarity of expectations, fairness of rules, school safety, and bullying school-wide. Sample items are "School rules are fair" and "Teachers care about their students". These items were rated on a fourpoint scale (from $1=$ very inconsistent to $5=$ very consistent). A higher mean score indicated that the participants perceived a positive school climate. The Chinese version of the SC has demonstrated 
INTERPARENTAL CONFLICT AND RISK-TAKING BEHAVIOR

good internal consistency in adolescents (Wang et al., 2021). The Cronbach's alpha of this scale was 0.94 in the present study.

\section{Risk-taking behavior}

The participants completed the Adolescent Risk-taking Questionnaire (ARQ) at T1, T2, and T3 (Gullone et al., 2000); the ARQ is an 11-item questionnaire that measures how often respondents have engaged in risk-taking behavior (e.g., smoking, taking drugs, cheating), using a five-point scale ranging from $0=$ never, to $4=$ always). The scale consists of three dimensions: rebellious risk, reckless, and antisocial behavior. The Chinese version of the ARQ showed good internal consistency (Ju et al., 2020). The Cronbach's alpha values for the scale were $0.80,0.84$, and 0.83 at Time 1 , Time 2 , and Time 3, respectively.

\section{Demographic covariates}

Demographic covariates included adolescent age, adolescent sex $(1=$ boys; $2=$ girls $)$, and father's and mother's education level $(1=$ primary school and below; 2 = middle school degree; $3=$ undergraduate degree or equivalent; 4 = graduate degree).

\section{Analytic strategies}

The data were analyzed in IBM SPSS 26.0 and Mplus 8.3 with .05 as the level of significance. First, descriptive statistics and bivariate correlation analysis were conducted for all the variables of interest. Second, we performed a structural equation model in Mplus 8.3 (Muthén \& Muthén, 2012) to test hypotheses 1 and 2. With the bootstrapping $(N=5000)$ technique (Preacher \& Hayes, 2008) 
and its $95 \%$ confidence interval (IC) to estimate the significance of the (moderated) mediation effect, we tested the mediating effects of T2 DPA between T1 IPC and T3 risk-taking behavior. Third, we integrated the moderator (i.e., school climate) into the aforementioned mediation model to test hypotheses $3 \mathrm{a}$ and $3 \mathrm{~b}$. This allowed us to examine the extent to which school climate moderates the association between T2 DPA and T3 risk-taking behavior and to examine the extent to which school climate moderates the mediation effects of DPA.

\section{RESULTS}

\section{Descriptive and correlations}

Descriptive statistics and correlations among primary study variables are presented in Table 1. Specifically, T1 IPC was negatively related to T3 school climate and positively related to T2 DPA and T1/T2/T3 risk-taking behavior. In addition, T2 DPA was negatively related to T3 school climate and positively related to T1/T2/T3 risk-taking behavior. Moreover, the T3 school climate was negatively related to $\mathrm{T} 1 / \mathrm{T} 2 / \mathrm{T} 3$ risk-taking behavior.

[INSERT TABLE 1 IN HERE]

\section{Mediating effects of deviant peer affiliation}

The mediation model represented in Figure 2 revealed a good fit to the data: $\chi^{2}=90.95, d f=23$, $p<0.001 ; \mathrm{RMSEA}=0.07$ with a $90 \% \mathrm{CI},[0.058,0.089]$; $\mathrm{CFI}=0.943$ and $\mathrm{SRMR}=0.041$. After controlling for covariates and T1/T2 risk-taking behavior, T1 IPC was significantly related to T2 DPA $(B=0.18, S E=0.05, p<0.001)$ but insignificantly related to T3 risk-taking behavior $(B=0.05, S E$ 
INTERPARENTAL CONFLICT AND RISK-TAKING BEHAVIOR

$=0.03, p=0.063)$. The results of the mediation analyses indicated that the mediation effect of T2 DPA was significant (indirect effect $=0.02, S E=0.01,95 \% \mathrm{CI}=[0.008,0.046])$.

\section{[INSERT FIGURE 2 IN HERE]}

[INSERT TABLE 2 IN HERE]

\section{Moderating effects of school climate}

Based on the testing for the mediation model, we continued to examine whether T3 school climate moderates the relation between T2 DPA and T3 risk-taking behavior as well as the mediating effect of T2 DPA. The moderated mediation model implied a good fit to the data: $\chi^{2}=129.31, d f=$ $29, p<0.001$; RMSEA $=0.079$ with a $90 \% \mathrm{CI}=[0.066,0.093]$; $\mathrm{CFI}=0.919$ and $\mathrm{SRMR}=0.034$ The results are displayed in Table 3, which suggested that T3 school climate moderated the relation between T2 DPA and T3 risk-taking behavior $(B=-0.10, S E=0.04, p=0.017, \beta=-0.10)$. Subsequently, the follow-up simple slope analysis (Figure 3) revealed that the relation between T2 DPA and T3 risk-taking behavior was stronger in low T3 school climates $(B=0.05, S E=0.02, p<$ $0.05)$ than in high T3 school climates $(B=0.02, S E=0.02, p=0.210)$.

\section{[INSERT TABLE 3 IN HERE]}

\section{[INSERT FIGURE 3 IN HERE]}

As illustrated in Table 4, the moderated mediation model indicated that the indirect effect of T2 DPA was significantly stronger when the T3 school climate was low $(B=0.05, S E=0.01,95 \% \mathrm{CI}=$ $[0.021,0.072])$ than when the T3 school climate was high $(B=0.03, S E=0.01,95 \% \mathrm{CI}=[0.015$, 0.055]). In summary, we conclude that IPC has a stronger negative association with adolescents' risktaking behavior via DPA when school climate is lower. The results supported hypotheses $3 \mathrm{a}$ and $3 \mathrm{~b}$. 


\section{[INSERT TABLE 4 IN HERE]}

\section{DISCUSSION}

Based on the ecological system theory perspective, the present study examined the longitudinal association between IPC and risk-taking behavior among Chinese adolescents and investigated the underlying mediating and moderating mechanisms. Moreover, the multiple development contexts (i.e., family and school) better reveal the developmental courses of adolescents' risk-taking behavior than a single development context. The primary findings of this study were that DPA mediates the association between IPC and risk-taking behavior, especially in a low-level school climate. Additionally, this study used a short-term longitudinal design to measure the core variables. This procedure addressed previous research focused primarily on cross-sectional methodology and thus is conducive to causal inference and controlling for common method bias. Such a design has been widely used in previous research (Boer et al., 2021; Cooper et al., 2020; Wang et al., 2021).

\section{The association between IPC and risk-taking behavior}

Based on family system theory (Bowen, 1966), the family is the primary place for adolescents to obtain growth resources. Compared to previous cross-sectional studies (Ai et al., 2017; Harold et al., 2012), the present study found a longitudinal association between IPC and adolescents' risktaking behavior after controlling for the baseline levels of risk-taking behavior, which confirmed hypothesis 1 . This is also in line with a longitudinal study by Koçak et al. (2017), where IPC was also a positive predictor of risk-taking behavior. IPC might signify inadequate family support resources and poor parent-child relationships (Davies et al., 2018; Fosco \& Grych, 2010; Mastrotheodoros et 
al., 2019). This may result in adolescents' risk-taking behavior to help them relieve stresses from IPC (Davies et al., 2016; Eldik et al., 2020).

\section{The mediation of deviant peer affiliation}

Consistent with hypothesis 2 , the results showed that exposure to DPA not only was a consequence of IPC but also played a mediating role in the relationship between IPC and risk-taking behavior. Our findings are consistent with those of previous studies; IPC motivated adolescents to affiliate with deviant peers, and this was further associated with more risk-taking behavior (Bowman et al., 2007; Ding et al., 2020). Furthermore, the current study, which was based on the ecological system (Bronfenbrenner, 1979), emphasizes that the family and peer contexts are dual ecological risk factors that promote adolescents' risk-taking behavior. Although peers become more influential as children enter adolescence, they do not supplant parents as the main sources of influence on adolescents' behavior (Brown \& Bakken, 2011). Previous research has demonstrated that family risk factors (i.e., IPC) may affect adolescents' choices of friends and peer groups and prompt them to choose an adverse peer context (Mehus et al., 2018). When parents fail to teach a correct view of making friends, this facilitates adolescent exposure to DPA and engaging in risk-taking behavior (Daspe et al., 2019). In addition, adolescents who are frequently exposed to IPC are particularly susceptible to social difficulties such as peer interaction issues, poor social competence, and DPA (Davies et al., 2018). To gain peer acceptance and support, adolescents may engage in more peer-led risk-taking behavior (Graupensperger et al., 2019). 


\section{The moderation of school climate}

Another important finding was that the mediation effect of DPA was moderated by school climate. In comparison to the high level of school climate, the low level of school climate enhanced the adverse effect of DPA on risk-taking behavior. Our findings are in line with those of previous research that demonstrated that school context facilitates the deteriorative effect of DPA on adolescent development (Wang et al., 2020). One potential explanation is that a negative school climate can meet the needs of affiliating with deviant peers and send a message to the student that their behavior may not be supervised by school rules, thereby reinforcing risk-taking behavior (Sullivan et al., 2021). In addition, our findings do not support the stress-buffering model, and the protective effect of the positive school climate seems to attenuate as the level of DPA increases. Concerning this, DeLay et al. (2016) demonstrated that friendship choices have a lasting impact on adolescent deviance, and adolescents who choose to affiliate with deviant peers are less able to capitalize on the benefits of a positive context and may engage in more risk-taking behavior. The present study contributes to the existing research and highlights the importance of microsystems (i.e., low school climate) in enhancing the negative effect between DPA and risk-taking behavior. In creating prevention and intervention strategies, the importance of school climate should be considered.

\section{Implications}

Multiple theoretical and practical implications can be drawn to reduce adolescents' risk-taking behavior. First, the impact of IPC on adolescents' behavioral development deserves attention. Parents should avoid or reduce conflict to construct a harmonious family environment for adolescents. More importantly, given that IPC may increase risk-taking behavior via DPA among adolescents, they 
should be encouraged to participate in positive peer interactions and reduce DPA should be noteworthy. Second, it is critical to pay more attention to adolescents who perceive a negative school climate and to enhance teacher-student communication and support, which may help reduce deviant peer influence and risk-taking behavior among adolescents (Li et al., 2013; Teng et al., 2020; Wang, 2009). Finally, our moderated mediation model demonstrated that adolescent risk-taking behavior is the joint effect of the risk factors from parents, peers, and school microsystems. Thus, it is necessary to comprehensively consider the multilevel risk and protection factors of family, peers, and school, rather than focusing on factors from only one aspect.

\section{Limitations and future directions}

Although this study provides important information about the underlying factors associated with risk-taking behavior in Chinese adolescents, several limitations still need to be mentioned. First, the sample in this study predominantly comprised Chinese adolescents recruited from a large metropolitan area and did not include rural and small city groups or special groups (e.g., left-behind children). Future work is required for the representativeness of the sample. Second, although this study used a three-point longitudinal design, the findings are still correlational in nature and do not suggest causality. Finally, data for all variables were derived from adolescent self-reports, and future studies may benefit from including multi-informant assessments (e.g., parent reports, teacher reports, peer reports) to improve ecological validity.

\section{CONCLUSION}

This three-point longitudinal study examined the underlying mechanism of how and for whom 
INTERPARENTAL CONFLICT AND RISK-TAKING BEHAVIOR

interparental conflict is related to risk-taking behavior in adolescents. Specifically, the present study demonstrates that interparental conflict is associated with risk-taking behavior through DPA in Chinese adolescents. Furthermore, a positive school climate serves as a protective factor to alleviate the negative impact of DPA on adolescents.

\section{REFERENCES}

Ai, T., Xu, Q., Li, X., \& Li, D. (2017). Interparental Conflict and Chinese Adolescents' Suicide Ideation and Suicide attempts: The Mediating Role of Peer Victimization. Journal of Child and Family Studies, 26(12), 3502-3511. https://doi.org/10.1007/s10826-017-0837-y

Albert, D., \& Steinberg, L. (2011). Judgment and decision making in adolescence. Journal of Research on Adolescence, 21(1), 211-224. https://doi.org/10.1111/j.1532-7795.2010.00724.x

Bao, Z., Jiang, Y., Zhu, J., \& Zhang, W. (2020). School connectedness and deviant peer affiliation among Chinese adolescents: the mediating role of sleep problems. Current Psychology, 39(2), 1-10. https://doi.org/10.1007/s12144-020-00731-2

Bao, Z., Li, D., Zhang, W., \& Wang, Y. (2015). School climate and delinquency among Chinese adolescents: analyses of effortful control as a moderator and deviant peer affiliation as a mediator. Journal of Abnormal Child Psychology, 43(1), 81-93. https://doi.org/10.1007/s10802-014-9903-8

Bear, G. G., Gaskins, C., Blank, J., \& Chen, F. F. (2011). Delaware School Climate Survey-Student: its factor structure, concurrent validity, and reliability. Journal of School Psychology, 49(2), 157-174. https://doi.org/10.1016/j.jsp.2011.01.001

Bear, G. G., Yang, C., Mantz, L., Pasipanodya, E., Hearn, S., \& Boyer, D. (2014). Technical manual for Delaware school survey: Scales of school climate, bullying victimization, student 
INTERPARENTAL CONFLICT AND RISK-TAKING BEHAVIOR

engagement, and positive, punitive, and social emotional learning techniques. Delaware Positive Behavior Support (DE-PBS) and School Climate Transformation Projects.

Ben-Zur, H., \& Zeidner, M. (2009). Threat to Life and Risk-Taking Behaviors: A Review of Empirical Findings and Explanatory Models. Personality and Social Psychology Review, 13, 109-128. https://doi.org/10.1177/1088868308330104

Blakemore, S. J. (2018). Avoiding Social Risk in Adolescence. Current Directions in Psychological Science, 27(2), 116-122. https://doi.org/10.1177/0963721417738144

Boer, M., Stevens, G. W. J. M., Finkenauer, C., de Looze, M. E., \& van den Eijnden, R. J. J. M. (2021). Social media use intensity, social media use problems, and mental health among adolescents: Investigating directionality and mediating processes. Computers in Human Behavior, 116, Article 106645. https://doi.org/10.1016/j.chb.2020.106645

Bowen, M. (1966). The use of family theory in clinical practice. Comprehensive Psychiatry, 7(5), 345-374. https://doi.org/10.1016/S0010-440X(66)80065-2

Bowman, M. A., Prelow, H. M., \& Weaver, S. R. (2007). Parenting Behaviors, Association with Deviant Peers, and Delinquency in African American Adolescents: A Mediated-Moderation Model. Journal of Youth and Adolescence, 36(4), 517-527. https://doi.org/10.1007/s10964006-9117-7

Brock, R. L., \& Kochanska, G. (2016). Interparental conflict, children's security with parents, and longterm risk of internalizing problems: A longitudinal study from ages 2 to 10. Development and Psychopathology, 28(1), 45-54. https://doi.org/10.1017/S0954579415000279

Bronfenbrenner, U. (1979). The ecology of human development. Harvard University Press.

Brown, B. B., \& Bakken, J. P. (2011). Parenting and Peer Relationships: Reinvigorating Research on 
INTERPARENTAL CONFLICT AND RISK-TAKING BEHAVIOR

Family-Peer Linkages in Adolescence. Journal of Research on Adolescence, 21(1), 153-165. https://doi.org/10.1111/j.1532-7795.2010.00720.x

Buehler, C., Krishnakumar, A., Stone, G., Anthony, C., Pemberton, S., Gerard, J., \& Barber, B. K. (1998). Interparental conflict styles and youth problem behaviors A two-sample replication study. Journal of Marriage and the Family, 60, 119-132. https://doi.org/10.2307/353446

Capaldi, D. M., Tiberio, S. S., Shortt, J. W., Low, S., \& Owen, L. D. (2020). Associations of exposure to intimate partner violence and parent-to-child aggression with child competence and psychopathology symptoms in two generations. Child Abuse \& Neglect, 103, Article 104434. https://doi.org/10.1016/j.chiabu.2020.104434

Caravita, S. C. S., Papotti, N., Gutierrez Arvidsson, E., Thornberg, R., \& Valtolina, G. G. (2021). Contact with migrants and perceived school climate as correlates of bullying toward migrants classmates. Child \& Adolescent Development, 177, 1-17. https://doi.org/10.1002/cad.20400

Chen, C., Yang, C., Chan, M., \& Jimerson, S. R. (2020). Association between school climate and bullying victimization: Advancing integrated perspectives from parents and cross-country comparisons. School Psychology, 35(5), 311-320. https://doi.org/10.1037/spq0000405

Chen, W., Li, D., Bao, Z., Yan, Y., \& Zhou, Z. (2015). The Impact of Parent-Child Attachment on Adolescent Problematic Internet Use: A Moderated Mediation Model. Acta Psychologica Sinica, 47(5), 611-623. https://doi.org/10.3724/sp.J.1041.2015.00611

Coelho, V. A., Bear, G. G., \& Bras, P. (2020). A Multilevel Analysis of the Importance of School Climate for the Trajectories of Students' Self-concept and Self-esteem Throughout the Middle School Transition. Journal of Youth and Adolescence, 49(9), 1793-1804. https://doi.org/10.1007/s10964-020-01245-7 
INTERPARENTAL CONFLICT AND RISK-TAKING BEHAVIOR

Cooper, B., Eva, N., Zarea Fazlelahi, F., Newman, A., Lee, A., \& Obschonka, M. (2020). Addressing common method variance and endogeneity in vocational behavior research: A review of the literature and suggestions for future research. Journal of Vocational Behavior, 121, Article 103472. https://doi.org/10.1016/j.jvb.2020.103472

Daspe, M. E., Arbel, R., Ramos, M. C., Shapiro, L. A. S., \& Margolin, G. (2019). Deviant Peers and Adolescent Risky Behaviors: The Protective Effect of Nonverbal Display of Parental Warmth. Journal of Research on Adolescence, 29(4), 863-878. https://doi.org/10.1111/jora.12418

Davies, P. T., Hentges, R. F., Coe, J. L., Martin, M. J., Sturge-Apple, M. L., \& Cummings, E. M. (2016). The multiple faces of interparental conflict: Implications for cascades of children's insecurity and externalizing problems. Journal of Abnormal Psychology, 125(5), 664-678. https://doi.org/10.1037/abn0000170

Davies, P. T., Martin, M. J., \& Cummings, E. M. (2018). Interparental conflict and children's social problems: Insecurity and friendship affiliation as cascading mediators. Developmental Psychology, 54(1), 83-97. https://doi.org/10.1037/dev0000410

DeLay, D., Ha, T., Van Ryzin, M., Winter, C., \& Dishion, T. J. (2016). Changing Friend Selection in Middle School: A Social Network Analysis of a Randomized Intervention Study Designed to Prevent Adolescent Problem Behavior. Prevention Science, 17(3), 285-294. https://doi.org/10.1007/s11121-015-0605-4

Ding, Y., Li, D., Li, X., Xiao, J., Zhang, H., \& Wang, Y. (2020). Profiles of adolescent traditional and cyberbullying and victimization: The role of demographic, individual, family, school, and peer factors. Computers in Human Behavior, 111, Article 106439. https://doi.org/10.1016/j.chb.2020.106439 
INTERPARENTAL CONFLICT AND RISK-TAKING BEHAVIOR

Dorio, N. B., Clark, K. N., Demaray, M. K., \& Doll, E. M. (2019). School Climate Counts: A Longitudinal Analysis of School Climate and Middle School Bullying Behaviors. International Journal of Bullying Prevention, 2(4), 292-308. https://doi.org/10.1007/s42380019-00038-2

Dou, K., Lin, X. Q., \& Wang, Y. J. (2020). Negative parenting and risk-taking behaviors in Chinese adolescents: Testing a sequential mediation model in a three-wave longitudinal study. Children and Youth Services Review, 119(4), Article 105631. https://doi.org/10.1016/j.childyouth.2020.105631

Duell, N., Steinberg, L., Icenogle, G., Chein, J., Chaudhary, N., Di Giunta, L., Dodge, K. A., Fanti, K. A., Lansford, J. E., Oburu, P., Pastorelli, C., Skinner, A. T., Sorbring, E., Tapanya, S., Uribe Tirado, L. M., Alampay, L. P., Al-Hassan, S. M., Takash, H. M. S., Bacchini, D., \& Chang, L. (2018). Age Patterns in Risk Taking Across the World. Journal of Youth and Adolescence, 47(5), 1052-1072. https://doi.org/10.1007/s10964-017-0752-y

Eldik, W. M., Haan, A. D., Arends, L. R., \& Prinzie, P. (2020). Moderation of associations between interparental stress and (mal)adaptation by adolescents' personality: Contrasting differential susceptibility and diathesis-stress models. Journal of Personality, 89(4), 617-633. https://doi.org/10.1111/jopy.12603

Fosco, G. M., \& Grych, J. H. (2010). Adolescent Triangulation Into Parental Conflicts: Longitudinal Implications for Appraisals and Adolescent-Parent Relations. Journal of Marriage and Family, 72(2), 254-266. https://doi.org/10.1111/j.1741-3737.2010.00697.x

Fosco, G. M., Lippold, M., \& Feinberg, M. (2014). Interparental Boundary Problems, ParentAdolescent Hostility, and Adolescent-Parent Hostility: A Family Process Model for 
INTERPARENTAL CONFLICT AND RISK-TAKING BEHAVIOR

Adolescent Aggression Problems. Couple and Family Psychology, 3(3), 141-155. https://doi.org/10.1037/cfp0000025

Freeman, C., Dirks, M., \& Weinberg, A. (2020). Neural response to rewards predicts risk-taking in late but not early adolescent females. Developmental Cognitive Neuroscience, 45, Article 100808. https://doi.org/10.1016/j.dcn.2020.100808

Graupensperger, S., Benson, A. J., Bray, B. C., \& Evans, M. B. (2019). Social cohesion and peer acceptance predict student-athletes' attitudes toward health-risk behaviors: A within- and between-group investigation. Journal of Science and medicine in sport, 22(12), 1280-1286. https://doi.org/10.1016/j.jsams.2019.07.003

Gullone, E., Moore, S., Moss, S., \& Boyd, C. (2000). The Adolescent Risk-Taking Questionnaire. Journal of Adolescent Research, 15(2), 231-250. https://doi.org/10.1177/0743558400152003

Harold, G. T., Elam, K. K., Lewis, G., Rice, F., \& Thapar, A. (2012). Interparental conflict, parent psychopathology, hostile parenting, and child antisocial behavior: examining the role of maternal versus paternal influences using a novel genetically sensitive research design. Development and Psychopathology, 24(4), 1283-1295. https://doi.org/10.1017/S0954579412000703

Ju, C., Wu, R., Zhang, B., You, X., \& Luo, Y. (2020). Parenting style, coping efficacy, and risktaking behavior in Chinese young adults. Journal of Pacific Rim Psychology, 14, 1-9. https://doi.org/10.1017/prp.2019.24

Keeports, C. R., \& Pittman, L. D. (2016). I Wish My Parents Would Stop Arguing! The Impact of Interparental Conflict on Young Adults. Journal of Family Issues, 38(6), 839-857. https://doi.org/10.1177/0192513x15613821

Kerig, P. K. (1996). Assessing the links between interparental conflict and child adjustment The 
INTERPARENTAL CONFLICT AND RISK-TAKING BEHAVIOR

conflicts and problem-solving scales. Journal of Family Psychology, 10(4), 454-473. https://doi.org/10.1037/0893-3200.10.4.454

Koçak, A., Mouratidis, A., Sayıl, M., Kındap-Tepe, Y., \& Uçanok, Z. (2017). Interparental Conflict and Adolescents' Relational Aggression and Loneliness: The Mediating Role of Maternal Psychological Control. Journal of Child and Family Studies, 26(12), 3546-3558. https://doi.org/10.1007/s10826-017-0854-x

Kopec, A. M., Smith, C. J., Ayre, N. R., Sweat, S. C., \& Bilbo, S. D. (2018). Microglial dopamine receptor elimination defines sex-specific nucleus accumbens development and social behavior in adolescent rats. Nature Communications, 9, Article 3769. https://doi.org/10.1038/s41467-018-06118-z

Li, D., Li, X., Wang, Y., Zhao, L., Bao, Z., \& Wen, F. (2013). School connectedness and problematic internet use in adolescents: a moderated mediation model of deviant peer affiliation and self-control. Journal of Abnormal Child Psychology, 41(8), 1231-1242. https://doi.org/10.1007/s10802-013-9761-9

López-Larrosa, S., Mendiri, P., \& Sánchez-Souto, V. (2019). Exploring the relationship between interparental conflict and emotional security: What happens with adolescents in residential care compared to those living with their families? Children and Youth Services Review, 101, 123-130. https://doi.org/10.1016/j.childyouth.2019.03.054

Loukas, A., Cance, J. D., \& Batanova, M. (2016). Trajectories of School Connectedness Across the Middle School Years. Youth \& Society, 48(4), 557-576. https://doi.org/10.1177/0044118x13504419

Lux, U., \& Walper, S. (2019). A systemic perspective on children's emotional insecurity in relation to 
INTERPARENTAL CONFLICT AND RISK-TAKING BEHAVIOR

father: links to parenting, interparental conflict and children's social well-being. Attachment \& Human Development, 21(5), 467-484. https://doi.org/10.1080/14616734.2019.1582597

Martin, M. J., Conger, R. D., \& Robins, R. W. (2019). Family stress processes and drug and alcohol use by Mexican American adolescents. Development Psychology, 55(1), 170-183. https://doi.org/10.1037/dev0000629

Mastrotheodoros, S., Van der Graaff, J., Deković, M., Meeus, W. H. J., \& Branje, S. J. T. (2019). Interparental Conflict Management Strategies and Parent-Adolescent Relationships: Disentangling Between-Person from Within-Person Effects Across Adolescence. Journal of Marriage and Family, 81(1), 185-203. https://doi.org/https://doi.org/10.1111/jomf.12528

McCoy, S. S., Dimler, L. M., Samuels, D. V., \& Natsuaki, M. N. (2017). Adolescent Susceptibility to Deviant Peer Pressure: Does Gender Matter? Adolescent Research Review, 4(1), 59-71. https://doi.org/10.1007/s40894-017-0071-2

Mehus, C. J., Forster, M., Chan, G., Hemphill, S. A., Toumbourou, J. W., \& McMorris, B. J. (2018). Longitudinal, reciprocal relationships between family management and antisocial peer associations. Journal of Adolescence, 68, 146-151. https://doi.org/10.1016/j.adolescence.2018.07.015

O'Hara, K. L., Sandler, I. N., Wolchik, S. A., Thin, J. Y., \& Rhodes, C. A. (2019). Parenting Time, Parenting Quality, Interparental Conflict, and Mental Health Problems of Children in High-Conflict Divorce. Journal of Family Psychology, 33(6), 690-703. https://doi.org/10.1037/fam0000556

Ohannessian, C. M., \& Vannucci, A. (2020). Adolescent Psychological Functioning and Membership in Latent Adolescent-Parent Communication Dual Trajectory Classes. Journal of Research 
INTERPARENTAL CONFLICT AND RISK-TAKING BEHAVIOR

on Adolescence, 30, 66-86. https://doi.org/10.1111/jora.12442

Orgiles, M., Carratala, E., \& Espada, J. P. (2015). Perceived quality of the parental relationship and divorce effects on sexual behaviour in Spanish adolescents. Psychology Health \& Medicine, 20(1), 8-17. https://doi.org/10.1080/13548506.2014.911922

Peng, S., Zhou, B., Wang, X., Zhang, H., \& Hu, X. (2020). Does high teacher autonomy support reduce smartphone use disorder in Chinese adolescents? A moderated mediation model. Addictive Behaviors, 105, Article 106319. https://doi.org/10.1016/j.addbeh.2020.106319

Rudolph, K. D., Lansford, J. E., Agoston, A. M., Sugimura, N., Schwartz, D., Dodge, K. A., Pettit, G. S., \& Bates, J. E. (2014). Peer victimization and social alienation: predicting deviant peer affiliation in middle school. Child Development, 85(1), 124-139. https://doi.org/10.1111/cdev.12112

Sanci, L., Webb, M., \& Hocking, J. (2018). Risk-taking behaviour in adolescents. Australian Journal of General Practice, 47, 829-834. https://doi.org/10.31128/AJGP-07-18-4626

Sullivan, K., Zhu, Q., Wang, C., \& Boyanton, D. (2021). Relations Among Peer Victimization, Aggression, and School Climate Among Elementary School Students in China. School Psychology Review, 1-13. https://doi.org/10.1080/2372966X.2021.1898290

Sznitman, S. R., \& Romer, D. (2014). Student drug testing and positive school climates Testing the relation between two school characteristics and drug use behavior in a longitudinal study. Journal of Studies on Alcohol and Drugs, 75(1), 65-73. https://doi.org/10.15288/jsad.2014.75.65

Teng, Z., Bear, G. G., Yang, C., Nie, Q., \& Guo, C. (2020). Moral disengagement and bullying perpetration: A longitudinal study of the moderating effect of school climate. School 
INTERPARENTAL CONFLICT AND RISK-TAKING BEHAVIOR

Psychology, 35(1), 99-109. https://doi.org/10.1037/spq0000348

Thompson, E. L., Mehari, K. R., \& Farrell, A. D. (2020). Deviant Peer Factors During Early Adolescence: Cause or Consequence of Physical Aggression? Child Development, 91(2), 415-431. https://doi.org/10.1111/cdev.13242

van Eldik, W. M., de Haan, A. D., Parry, L. Q., Davies, P. T., Luijk, M., Arends, L. R., \& Prinzie, P. (2020). The interparental relationship: Meta-analytic associations with children's maladjustment and responses to interparental conflict. Psychological Bulletin, 146(7), 553-594. https://doi.org/10.1037/bu10000233

Varela, J. J., Sánchez, P. A., De Tezanos-Pinto, P., Chuecas, J., \& Benavente, M. (2021). School Climate, Bullying and Mental Health among Chilean Adolescents. Child Indicators Research, 14, 2249-2264. https://doi.org/10.1007/s12187-021-09834-z

Walker, D. A., \& Holtfreter, K. (2019). Teen Pregnancy, Depression, and Substance Abuse: The Conditioning Effect of Deviant Peers. Deviant Behavior, 42(3), 1-16. https://doi.org/10.1080/01639625.2019.1666610

Wang, L. X., Dou, K., Li, J. B., Zhang, M. C., \& Guan, J. Y. (2021). The association between interparental conflict and problematic internet use among Chinese adolescents: Testing a moderated mediation model. Computers in Human Behavior, 122, Article 106832. https://doi.org/10.1016/j.chb.2021.106832

Wang, M. T. (2009). School climate support for behavioral and psychological adjustment: Testing the mediating effect of social competence. School Psychology Quarterly, 24(4), 240-251. https://doi.org/10.1037/a0017999

Wang, M. T., \& Dishion, T. J. (2012). The Trajectories of Adolescents' Perceptions of 
INTERPARENTAL CONFLICT AND RISK-TAKING BEHAVIOR

School Climate, Deviant Peer Affiliation, and Behavioral Problems During the Middle School Years. Journal of Research on Adolescence, 22(1), 40-53. https://doi.org/10.1111/j.1532-7795.2011.00763.x

Wang, Z., Liu, C., Li, T., \& Zhao, F. (2020). Paternal parenting and depressive symptoms among adolescents: A moderated mediation model of deviant peer affiliation and school climate. Children and Youth Services Review, 119, Article 105630. https://doi.org/10.1016/j.childyouth.2020.105630

Weymouth, B. B., Fosco, G. M., Mak, H. W., Mayfield, K., LoBraico, E. J., \& Feinberg, M. E. (2019). Implications of interparental conflict for adolescents' peer relationships: A longitudinal pathway through threat appraisals and social anxiety symptoms. Developmental Psychology, 55(7), 1509-1522. https://doi.org/10.1037/dev0000731

Xu, F., Chen, X., Xing, H., \& Wang, H. (2021). Interparental Conflict and Chinese Children's Social Development. Journal of Family Issues, 1-22. https://doi.org/10.1177/0192513x211042843

Yang, C., Sharkey, J. D., Reed, L. A., \& Dowdy, E. (2020). Cyberbullying victimization and student engagement among adolescents: Does school climate matter? School Psychology, 35(2), 158-169. https://doi.org/10.1037/spq0000353

Zhang, M. C., Wang, L. X., Dou, K., \& Liang, Y. (2021). Why victimized by peer promotes cyberbullying in college students? Testing a moderated mediation model in a threewave longitudinal study. Current Psychology, Advance online publication. https://doi.org/10.1007/s12144-021-02047-1 


\section{Table 1}

The means, standard deviations, correlations among the variables

\begin{tabular}{|c|c|c|c|c|c|c|c|c|c|c|c|}
\hline & $M$ & $S D$ & 1 & 2 & 3 & 4 & 5 & 6 & 7 & 8 & 9 \\
\hline \multicolumn{12}{|l|}{ Covariates } \\
\hline 1. Student age at $\mathrm{T} 1$ & 15.37 & 1.35 & & & & & & & & & \\
\hline 2. Student gender & $47.56^{\mathrm{a}}$ & -- & 0.05 & & & & & & & & \\
\hline 3. Father's level of education & -- & -- & -0.05 & 0.05 & & & & & & & \\
\hline 4. Mother's level of education & -- & -- & -0.08 & 0.06 & $0.61^{* * *}$ & & & & & & \\
\hline \multicolumn{12}{|l|}{ Key variables } \\
\hline 5. T1 Interparental conflict & 1.10 & 0.47 & $-0.10^{*}$ & 0.05 & -0.02 & -0.06 & & & & & \\
\hline 6. T2 Deviant peer affiliation & 1.60 & 0.66 & -0.03 & -0.02 & 0.05 & 0.05 & $0.11^{*}$ & & & & \\
\hline 7. T3 School climate & 3.07 & 0.43 & $0.09^{*}$ & 0.01 & -0.01 & -0.01 & $-0.19^{* * *}$ & $-0.29^{* * *}$ & & & \\
\hline 8. T1 Risk-taking behavior & 0.39 & 0.34 & -0.03 & $-0.09^{*}$ & 0.05 & 0.01 & $0.20^{* * *}$ & $0.35^{* * *}$ & $-0.15^{* *}$ & & \\
\hline 9. T2 Risk-taking behavior & 0.42 & 0.38 & -0.06 & -0.04 & 0.07 & 0.02 & $0.16^{* * *}$ & $0.40^{* * *}$ & $-0.22^{* * *}$ & $0.49^{* * *}$ & \\
\hline 10. T3 Risk-taking behavior & 0.41 & 0.36 & -0.05 & -0.04 & 0.03 & 0.01 & $0.24^{* * *}$ & $0.39^{* * *}$ & $-0.26^{* * *}$ & $0.48^{* * *}$ & $0.63^{* * *}$ \\
\hline
\end{tabular}

$2=$ middle school, $3=$ undergraduate, $4=$ graduate student; ${ }^{\text {a }}$ The percentage of female adolescents; T1 = Time 1 , T2 = Time 2 , T3 = Time 3 . 
Table 2

Summary of the direct and indirect effects

\begin{tabular}{|c|c|c|c|c|}
\hline \multirow{2}{*}{ Direct and indirect effects } & \multicolumn{4}{|c|}{ Bias-Corrected Bootstrapped Estimates for the Effects } \\
\hline & Unstandardized & $S E$ & $95 \% \mathrm{CI}$ & Standardized \\
\hline \multicolumn{5}{|l|}{ Direct Pathway } \\
\hline T1 Interparental conflict $\rightarrow$ T3 Risk-taking behavior & 0.05 & $\mathbf{0 . 0 3}$ & {$[0.003,0.108]$} & 0.09 \\
\hline \multicolumn{5}{|l|}{ Indirect Pathways } \\
\hline $\mathrm{T} 1$ Interparental conflict $\rightarrow \mathrm{T} 2$ Deviant peer affiliation $\rightarrow \mathrm{T} 3$ Risk-taking behavior & $\mathbf{0 . 0 2}$ & 0.01 & {$[0.008,0.046]$} & 0.04 \\
\hline
\end{tabular}

Note: $\mathrm{T} 1=$ Time $1, \mathrm{~T} 2=$ Time $2, \mathrm{~T} 3=$ Time 3 ; The significant results are in bold. 
Table 3

Summary of the moderated mediation model

\begin{tabular}{|c|c|c|c|c|c|c|c|c|c|c|c|c|}
\hline & \multicolumn{4}{|c|}{ T2 Deviant peer affiliation $\left(R^{2}=0.03\right)$} & \multicolumn{4}{|c|}{ T2 Risk-taking behavior $\left(R^{2}=0.19\right)$} & \multicolumn{4}{|c|}{ T3 Risk-taking behavior $\left(R^{2}=0.48\right)$} \\
\hline & $B$ & $S E$ & $p$ & $\beta$ & $B$ & $S E$ & $p$ & $\beta$ & $B$ & $S E$ & $p$ & $\beta$ \\
\hline \multicolumn{13}{|l|}{ Covariates } \\
\hline Student age at $\mathrm{T} 1$ & & & & & & & & & 0.02 & 0.01 & 0.019 & 0.06 \\
\hline Student gender & & & & & & & & & -0.06 & $\mathbf{0 . 0 3}$ & 0.017 & -0.07 \\
\hline Father's level of education & & & & & & & & & 0.00 & 0.02 & 0.888 & -0.01 \\
\hline Mother's level of education & & & & & & & & & -0.01 & 0.03 & 0.720 & -0.01 \\
\hline \multicolumn{13}{|l|}{ Key variables } \\
\hline T1 Interparental conflict & 0.18 & 0.05 & $<0.001$ & 0.09 & 0.12 & 0.02 & $<0.001$ & 0.21 & 0.07 & $\mathbf{0 . 0 3}$ & 0.004 & 0.09 \\
\hline T2 Deviant peer affiliation & & & & & & & & & 0.21 & 0.02 & $<0.001$ & 0.31 \\
\hline T3 School climate & & & & & & & & & -0.01 & 0.02 & 0.541 & -0.02 \\
\hline T2 Deviant peer affiliation & & & & & & & & & -0.10 & 0.04 & 0.017 & -0.10 \\
\hline$\times$ T3 School climate & & & & & & & & & & & & \\
\hline T1 Risk-taking behavior & & & & & 0.19 & $\mathbf{0 . 0 3}$ & $<0.001$ & 0.34 & & & & \\
\hline T2 Risk-taking behavior & & & & & & & & & 0.21 & 0.02 & $<0.001$ & 0.16 \\
\hline
\end{tabular}




\section{Table 4}

Conditional indirect effects of T1 interparental conflict on T3 risk-taking behavior via T2 deviant peer affiliation by levels of T3 school climate

\begin{tabular}{|c|c|c|c|}
\hline Levels of T3 school climate & $B$ & $S E$ & $95 \% \mathrm{CI}$ \\
\hline Low $(M-S D)$ & 0.05 & 0.01 & {$[0.021,0.072]$} \\
\hline $\operatorname{Med}(M)$ & 0.04 & 0.01 & {$[0.019,0.062]$} \\
\hline $\operatorname{High}(M+S D)$ & $\mathbf{0 . 0 3}$ & 0.01 & {$[0.015,0.055]$} \\
\hline Diff (High - Low) & -0.01 & 0.01 & {$[-0.032,-0.004]$} \\
\hline
\end{tabular}

Note. $\mathrm{T} 1=$ Time $1, \mathrm{~T} 2=$ Time $2, \mathrm{~T} 3=$ Time 3 . The significant results are in bold. 


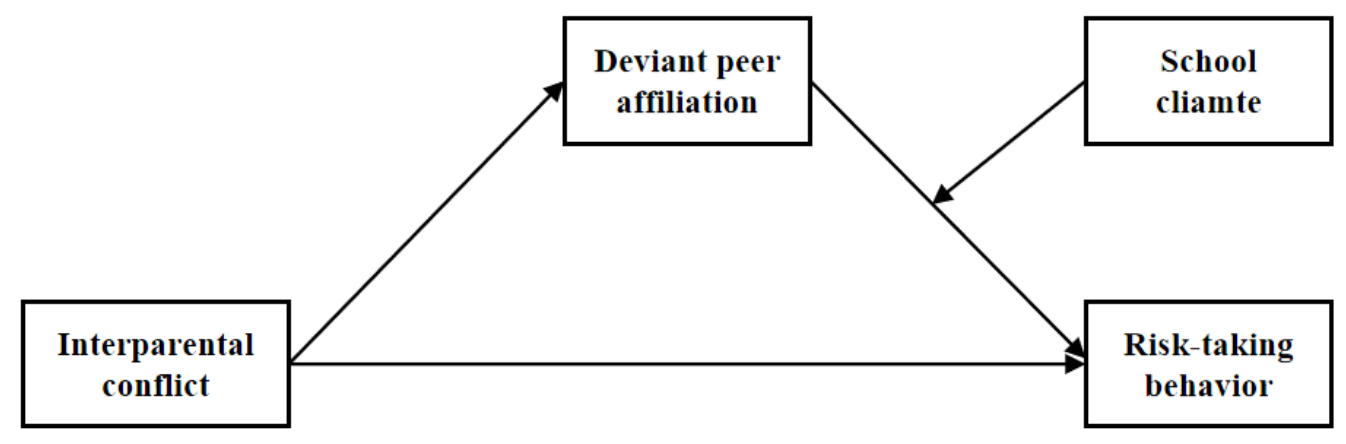

Figure 1. Conceptual moderated mediation model 


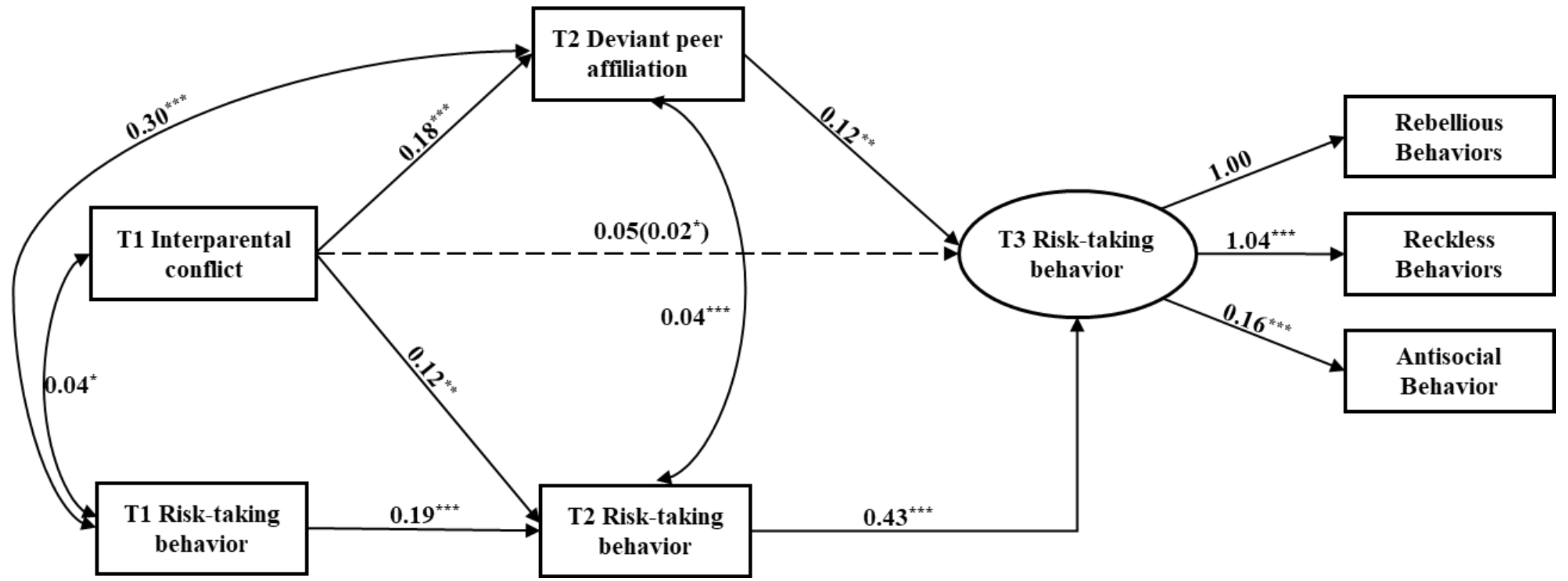

Figure 2. The mediating effect of $\mathrm{T} 2$ deviant peer affiliation in the relation between $\mathrm{T} 1$ interparental conflict and $\mathrm{T} 3$ risk-taking behavior Note: Unstandardized coefficients are reported; Student age, student gender, father's level of education, mother's level of education at Time 1 were included as covariates; ${ }^{*} p<0.05,{ }^{* *} p<0.01,{ }^{* * *} p<0.001 ; \mathrm{T} 1=$ Time $1, \mathrm{~T} 2=$ Time $2, \mathrm{~T} 3=$ Time 3 ; The value in parenthesis represent the direct effect, before incorporating mediation into the model. Dashed line indicates a non-significant coefficient. 


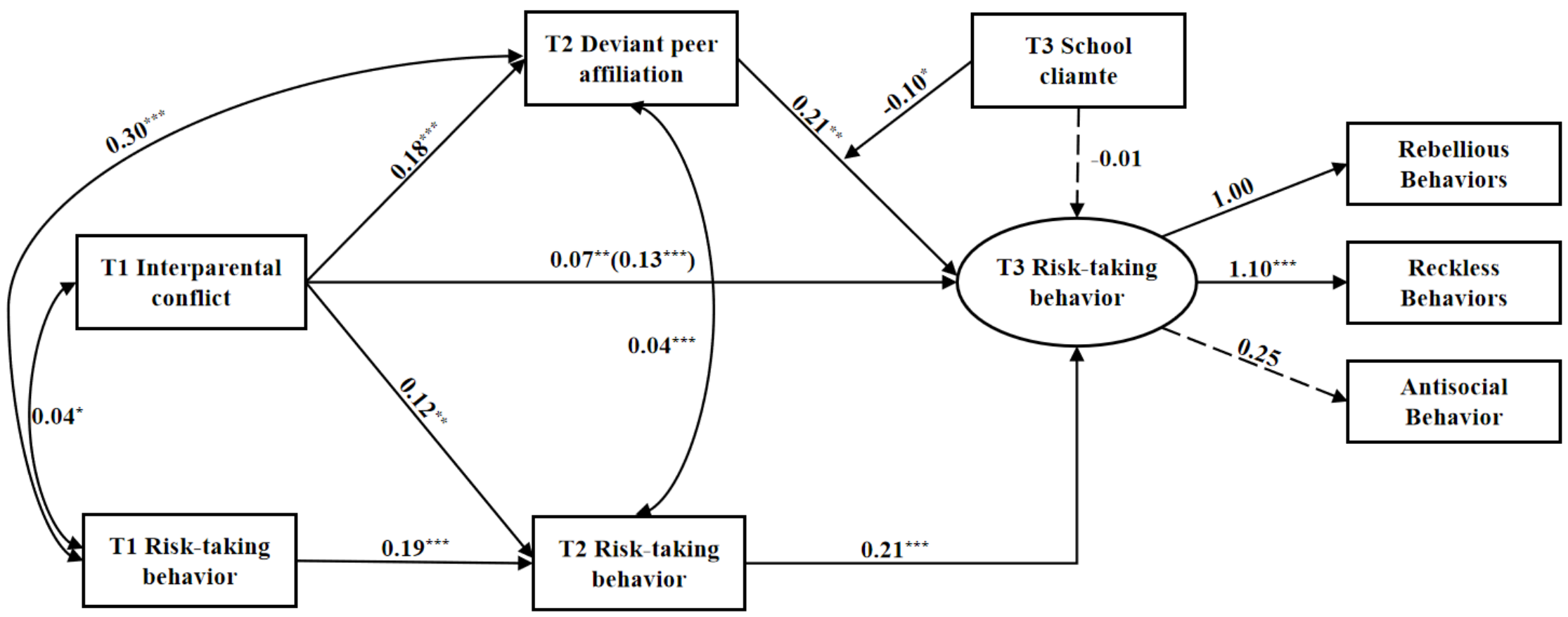

Figure 3. Moderated mediation model

Note: Unstandardized coefficients are reported; Student age, student gender, father's level of education, mother's level of education at Time 1 were included as covariates; ${ }^{*} p<0.05,{ }^{* *} p<0.01,{ }^{* * *} p<0.001 ; \mathrm{T} 1=$ Time $1, \mathrm{~T} 2=$ Time $2, \mathrm{~T} 3=$ Time 3 ; The value in parenthesis represent the direct effect, before incorporating mediation into the model. Dashed line indicates a non-significant coefficient. 


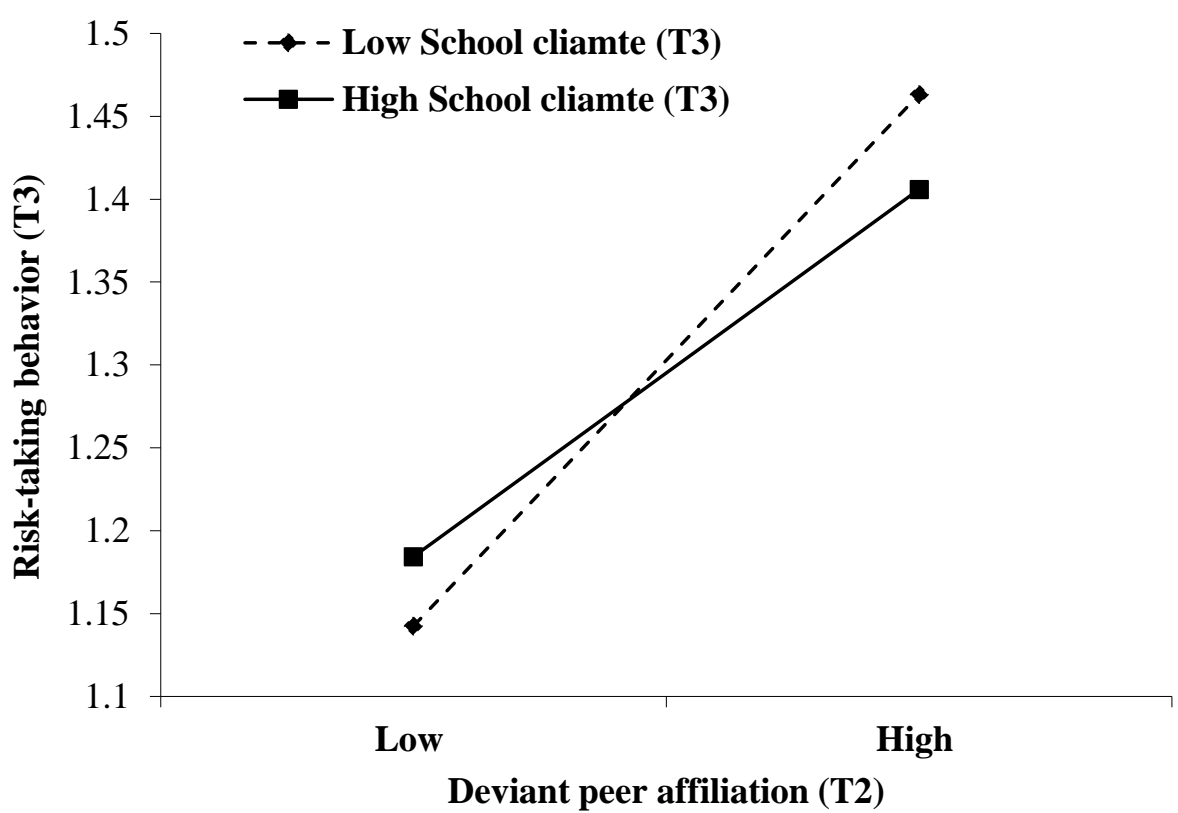

Figure 4. The relation between $\mathrm{T} 2$ deviant peer affiliation and $\mathrm{T} 3$ risk-taking behavior by $\mathrm{T} 3$ school climate. 